\title{
Adaptation of endovascular technique of self-expandable metal esophageal stent implantation in palliative treatment of malignant dysphagia in the course of esophageal and bronchial cancers: A one-center study
}

\author{
Damian Ziaja ${ }^{1,2, B}$, Bartłomiej Stasiów ${ }^{3, B}$, Mariola Sznapka ${ }^{2, B}$, Jolanta Domalik', , Wacław Kuczmik2,E, Krzysztof Ziaja ${ }^{2, A, E}$, Jerzy Chudek ${ }^{5, F}$ \\ ${ }^{1}$ Department of Physiotherapy, Faculty of Health Sciences in Katowice, Medical University of Silesia in Katowice, Poland \\ 2 Department of Department of General and Vascular Surgery, Faculty of Medical Sciences in Katowice, Medical University of Silesia in Katowice, Poland \\ ${ }^{3}$ Department of Radiology, Upper-Silesian Medical Centre in Katowice of Medical University of Silesia in Katowice, Poland \\ ${ }^{4}$ Department of General, Vascular and Transplant Surgery, Faculty of Medical Sciences in Katowice, Medical University of Silesia in Katowice, Poland \\ ${ }^{5}$ Department of Internal Diseases and Oncological Chemotherapy, Faculty of Medical Sciences in Katowice, Medical University of Silesia in Katowice, Poland \\ A - research concept and design; B - collection and/or assembly of data; $C$ - data analysis and interpretation; \\ $\mathrm{D}$ - writing the article; $\mathrm{E}$ - critical revision of the article; $\mathrm{F}$ - final approval of the article
}

\author{
Address for correspondence \\ Jerzy Chudek \\ E-mail: chj@poczta.fm \\ Funding sources \\ None declared \\ Conflict of interest \\ None declared

\section{Acknowledgements} \\ The modification of the technique was developed \\ without any knowledge of a similar approach \\ being developed in Qilu Hospital of Shandong \\ University, Jinan, China.
}

Received on December 22, 2018

Reviewed on March 22, 2019

Accepted on August 18, 2019

Cite as

Ziaja D, Stasiów B, Sznapka M, et al. Adaptation of endovascular technique of self-expandable metal esophageal stent implantation in palliative treatment of malignant dysphagia in the course of esophageal and bronchial cancers: A one-center study. Adv Clin Exp Med. 2020;29(11):1363-1366. doi:10.17219/acem/111810

DOI

10.17219/acem/111810

Copyright

Copyright by Author(s)

This is an article distributed under the terms of the

Creative Commons Attribution 3.0 Unported (CC BY 3.0)

(https://creativecommons.org/licenses/by/3.0/)

\begin{abstract}
Background. Esophageal stent implantation is an alternative for microjejunostomy or total parenteral nutrition in the palliative treatment of malignant dysphagia in the course of esophageal and advanced bronchial cancers infiltrating the esophagus. The procedure of implanting an esophageal self-expanding metal stent (SEMS) is performed with gastroscopic guidance under general anesthesia.
\end{abstract}

Objectives. To analyze the efficacy and safety of a simplified technique (without gastroscopic guidance in local anesthesia) of esophageal SEMS implantation in patients with malignant dysphagia in the course of esophageal and bronchial cancers.

Material and methods. This is a retrospective analysis of consecutive procedures of uncovered esophageal SEMS implantation performed with a simplified adaptation of the endovascular technique (Seldinger wire) in patients with esophageal and bronchial cancers and poor performance status. The procedures were done in a single surgical center over an 8-year period in 27 patients who were referred from oncology departments with esophageal stenosis confirmed using gastroscopy and who were being treated for malignant dysphagia. The study endpoints were effectiveness (a decrease in dysphagia from grade 3 or 4 to grade 1 after the procedure) and complications related to the procedures (including restenosis and stent migration).

Results. In all 27 patients, the SEMS were effectively implanted, enabling enteral nutrition after the procedure. No early complications related to the procedure were observed. A single patient developed restenosis 14 days after the procedure, which required re-stenting.

Conclusions. The simplified method for SEMS implantation described herein may be considered an option in the palliative treatment of patients with malignant dysphagia in the course of esophageal and bronchial cancers and poor performance status, especially in facilities with limited access to endoscopy.

Key words: esophageal cancer, bronchial cancer, self-expandable metal esophageal stent implantation, malignant dysphagia, palliative treatment 


\section{Introduction}

Dysphagia caused by cancer is a common and severe complication of locally advanced, unresectable or recurring cancers of the gastro-esophageal junction, and much less frequently from infiltration of bronchial carcinomas. It is followed by the rapid development of cachexia, which affects the quality of life and overall patient survival. ${ }^{1,2}$ At this stage of the disease, the priority is on supportive care and improving the patient's quality of life rather than curative treatment. ${ }^{3}$

Malnutrition can be reduced either by enteral nutrition through a jejunostomy or total parenteral nutrition. However, neither of these procedures resolves the problem of the patient's inability to swallow saliva, which leads to the severe complication of saliva aspirating into the airway. Therefore, restoration of esophageal patency is the only way to resolve this problem and improve their ability to swallow, and thus their quality of life. ${ }^{4}$

Currently, the most commonly used palliative treatment for dysphagia from cancer in patients with at least partial patency of the esophagus is stenting with self-expanding metal stents (SEMSs) of different types (fully covered, uncovered or partially covered). $3,5,6$ The choice of stent depends on the tumor size (length of the stenosis), its location and the morphology of the stenosis. ${ }^{3}$ A SEMS implant results in an immediate reduction in dysphagia and gives the patient the opportunity to take in fluids and food. 3,6 Stents are routinely placed over a guidewire positioned through gastroscopy and under fluoroscopic guidance during conscious sedation of the patient. In our center, this method was used until 2009.

In 2009, we introduced a simplified procedure of SEMS placement performed under local anesthesia only, without gastroscopic guidance, using a simplified adaptation of the endovascular technique (Seldinger wire).

In this paper, we describe the effective application of this modified method in a series of patients with dysphagia from cancer in the course of advanced or recurring esophageal and bronchial cancers.

\section{Patients and methods}

Between 2010 and 2017, 28 patients with esophageal stenosis and dysphagia who were in the course of advanced esophageal and bronchial cancers confirmed using gastroscopy, and who were disqualified from chemo- and radiotherapy due to poor performance status (Eastern Cooperative Oncology Group performance status 3 or 4), were referred from oncology centers to the Department General and Vascular Surgery. A SEMS implantation was performed in 27 patients with dysphagia of grade 3 or 4 unable to swallow liquids/saliva (Table 1). One patient was disqualified due to poor general clinical condition and died a few days later. Each patient gave written informed
Table 1. Characteristics of patients with cancer dysphagia $(n=27)$

\begin{tabular}{|c|c|}
\hline Parameter & Value \\
\hline Gender [men/women] & $18 / 9$ \\
\hline Age [years] & 62.5 (range: 52-87) \\
\hline Weight loss during the last 3-6 months [kg] & 17.5 (range: 10-35) \\
\hline Causes & Number of patients \\
\hline $\begin{array}{l}\text { Recurrence of gastro-esophageal junction } \\
\text { adenocarcinoma (after initial resection and } \\
\text { chemotherapy) }\end{array}$ & 8 \\
\hline $\begin{array}{l}\text { Progression of unresectable esophageal } \\
\text { squamous cell carcinoma (after chemo- and } \\
\text { radiotherapy) }\end{array}$ & 14 \\
\hline $\begin{array}{l}\text { Progression of bronchial carcinoma with } \\
\text { esophageal infiltration (after chemotherapy) }\end{array}$ & 5 \\
\hline
\end{tabular}

consent for the procedure. The study was conducted in accordance with the Declaration of Helsinki. The modification of the stenting procedure was reviewed by the Bioethical Committee of the Silesian Medical University in Katowice (approval No. NN-6501-53/06).

\section{Stenting procedure}

The procedures were performed at the Department of Radiology.

After local anesthesia of the mouth and throat with topical xylocaine spray, A 21Fr tube was introduced into the mouth to the level of the tumor while the patient was in a supine position. After removal of residual saliva from the esophagus using a 20 -milliliter syringe, $20 \mathrm{~mL}$ of iodine contrast was injected through the tube in order to visualize the stenotic canal and to manipulate the tumor under fluoroscopy (Fig. 1 - upper-left panel). We then withdrew the $21 \mathrm{Fr}$ tube by about $3 \mathrm{~cm}$, introducing through it a hydrophilic standard guidewire (0.035"; Terumo Interventional Systems, Somerset, USA), followed by Van Schie Seeking Catheters (2-3Fr, Cook Medical, Bloomington, USA), gently maneuvering into the stenotic channel to reach the stomach. After replacing the Van Schie Seeking Catheters with an extra-stiff guidewire (Lunderquist ${ }^{\circledR}$ Extra-Stiff Wire; Cook Medical, Bloomington, USA), we introduced a balloon with an uncovered SEMS. Finally, X-ray control was performed with iodine contrast at the end of the procedure (Fig. 1 - upper-right panel).

\section{Results}

The modified technique of esophageal SEMS implantation was successfully performed in all 27 patients, enabling enteral nutrition (liquid diet) immediately after the procedure (decreasing dysphagia from grade 3 or 4 to grade 1 ). No complications related to the procedure or migration of the SEMS was observed. One patient required a second SEMS due to re-stenosis 14 days after the $1^{\text {st }}$ procedure 

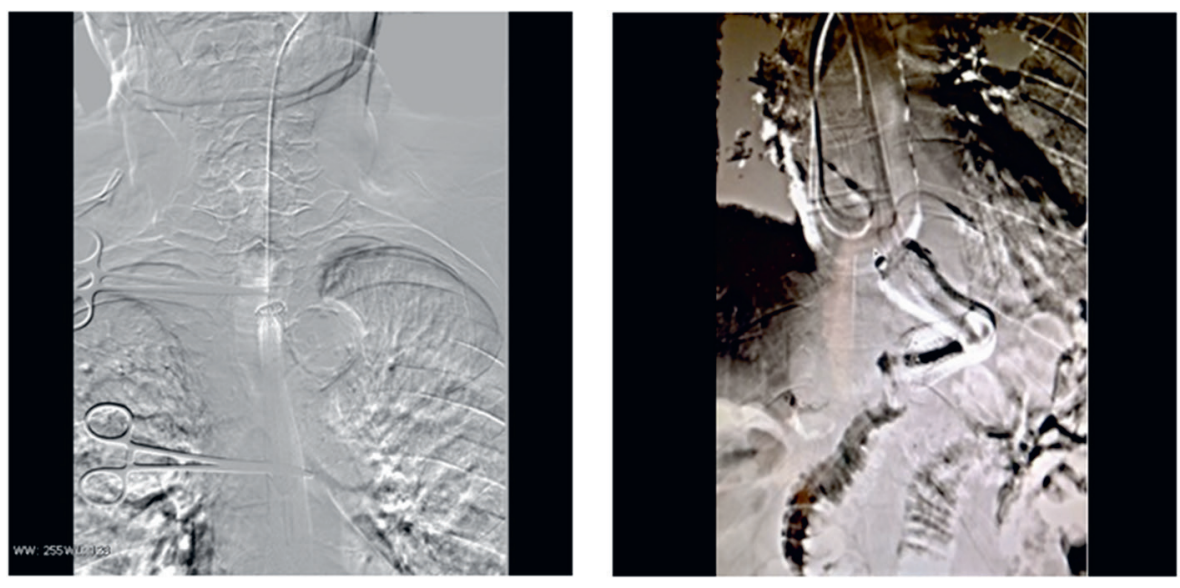

Fig. 1. The upper and lower borders

of the stenotic canal are marked using metal forceps fixed to the patient's skin (upperleft panel). Fluoroscopy (upper-right panel) after stent placement in a patient with an esophageal tumor infiltrating the trachea. Computed tomography after self-expanding metal replacement in a patient with stenosis recurrence (lower-left and -right panel)
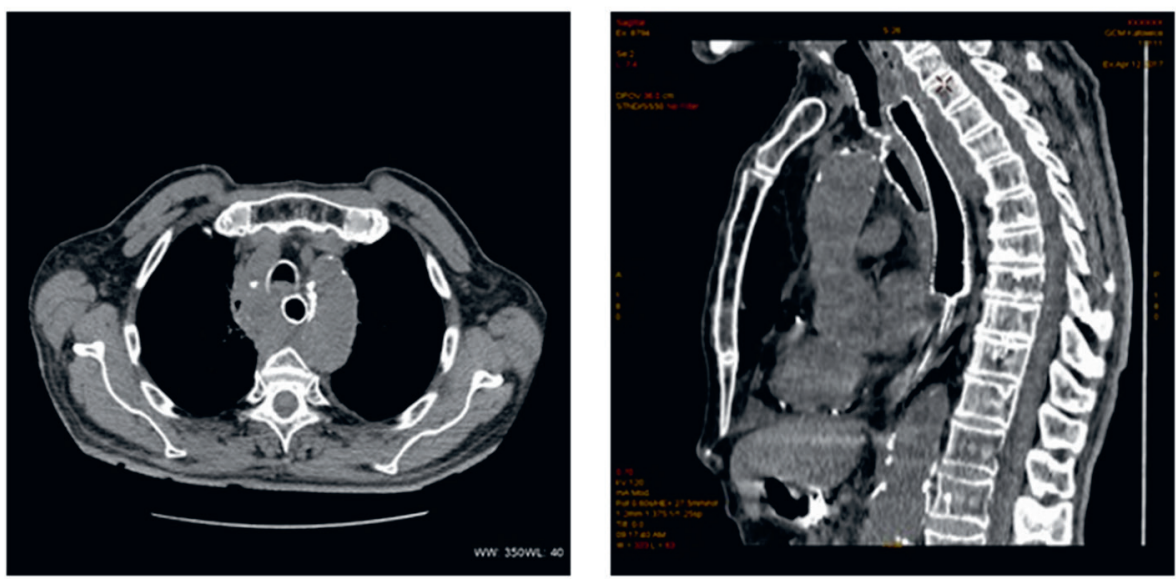

(Fig. 1 - lower-left and -right panels), and percutaneous endoscopic gastrostomy after another 28 days (40 days from the $1^{\text {st }}$ procedure).

All patients expressed satisfaction with the procedure in terms of restoring enteral nutrition. Almost half of the patients $(n=13)$ were discharged home with the recommendation of palliative care, while the others were transferred to district hospitals $(\mathrm{n}=11)$ or oncology units $(\mathrm{n}=3)$. The mean post-procedure survival time was 76 days (28-117 days).

\section{Discussion}

In our opinion, this modified procedure of esophageal SEMS implantation is a convenient alternative to the traditional procedure, with sedation provided by an anesthesiologist and the use of gastroscopy, or to the more invasive microjejunostomy or gastrostomy, in patients with esophageal stenosis and dysphagia from cancer, prevoiusly confirmed using gastroscopy (performed in other clinics as a part of a diagnostic work-up), especially in centers with limited access to endoscopy.

This simplified procedure of SEMS implantation is performed without an anesthesiologist or gastroscopy, and in consequence, is less expensive for the healthcare system. The technique is quite simple for qualified vascular surgeons, angiologists and interventional radiologists. It may be utilized in medical centers with limited access to gastroscopy. A quite similar approach has recently been described by Zhang et al. ${ }^{7}$ as a simple fluoroscopic method of SEMS insertion performed in 36 patients with dysphagia and fistula caused by esophageal carcinoma. They did not report clinically significant complications during or after the procedure.

Both our observations and those by Zhang et al. ${ }^{7}$ have proven the efficacy and safety of this procedure. Therefore, it seems that this method may be applied in other facilities even without large prospective, multicenter studies. We do not suggest that this method is better than the traditional approach. Certainly, endoscopic control has its advantages, e.g., direct identification of the residual lumen and evaluation of the stricture, which should ensure greater safety of the procedure. It should be stressed that in all of the patients in our study, endoscopy had already been performed in clinics which were unable to perform SEMS implantation, referring the patients to our center.

Esophageal brachytherapy is considered to be a suitable alternative to SEMS implantation, possibly providing a longer duration of improvement in symptoms and better quality of life ${ }^{8}$; however, the improvement in narrow stenosis can be achieved faster with SEMS implantation. ${ }^{9}$ In addition, esophageal stenting may be combined with brachytherapy ${ }^{10}$ or stents loaded with ${ }^{125}$ iodine seeds ${ }^{11}$ 
in patients with at least a three-month life expectancy in order to prevent restenosis. Nevertheless, in general, the majority of these palliatively treated patients have a short life expectancy, with a relatively low risk of restenosis. From our group of patients, with a mean period of survival of 76 days, a single patient developed restenosis and required re-stenting. We did not observe stent migration, which is more typical of covered stents, ${ }^{12}$ or other late complications (defined as events occurring at least 2-4 weeks after stenting) such as bleeding, perforation, gastroesophageal reflux disease, or chronic thoracic pain, which were previously reported after SEMS implantation. ${ }^{13}$

\section{Conclusions}

The simplified method for SEMS implantation described herein may be considered an option in palliative treatment for patients with malignant dysphagia in the course of esophageal and bronchial cancers and poor performance status, especially in centers with limited access to endoscopy.

\section{ORCID iDs}

Damian Ziaja (1) https://orcid.org/0000-0002-2348-2933 Bartłomiej Stasiów (10) https://orcid.org/0000-0001-6184-6948 Mariola Sznapka (ㄱ) https://orcid.org/0000-0001-7646-9997 Jolanta Domalik (1) https://orcid.org/0000-0001-5425-3247 Wacław Kuczmik (1) https://orcid.org/0000-0002-0927-0977 Krzysztof Ziaja (1) https://orcid.org/0000-0003-2230-5860 Jerzy Chudek (1) https://orcid.org/0000-0002-6367-7794

\section{References}

1. Watt $E$, Whyte $F$. The experience of dysphagia and its effect on the quality of life of patients with esophageal cancer. Eur J Cancer Care (Engl). 2003;12(2):183-193.

2. Anandavadivelan P, Lagergren P. Cachexia in patients with esophageal cancer. Nat Rev Clin Oncol. 2016;13(3):185-198.

3. Martinez JC, Puc MM, Quiros RM. Esophageal stenting in the setting of malignancy. ISRN Gastroenterology. 2011;2011:719575.

4. Reed CE, Marsh WH, Carlson LS, at al. Prospective, randomized trial of palliative treatment for unresectable cancer of the esophagus. Ann Thorac Surg. 1991;51(4):552-555.

5. Dormann AJ, Eisendrath $\mathrm{P}$, Wigginghaus $\mathrm{B}$, Huchzermeyer $\mathrm{H}$, Devière J. Palliation of esophageal carcinoma with a new self-expanding plastic stent. Endoscopy. 2003;35(3):207-211.

6. Madhusudhan C, Saluja SS, Pal S, et al. Palliative stenting for relief of dysphagia in patients with inoperable esophageal cancer: Impact on quality of life. Dis Esophagus. 2009;22(4):331-336.

7. Zhang K, Wei S, Wu J, Li C, Ma X, Wang Q. Palliation of malignant esophageal obstruction and fistulas with covered self-expandable metallic stents: Assessment of a simple fluoroscopic method. Int J Clin Exp Med. 2015;8(6):8860-8865.

8. Dai Y, Li C, Xie Y, et al. Interventions for dysphagia in esophageal cancer. Cochrane Database Syst Rev. 2014;10:CD005048.

9. Homs MY, Steyerberg EW, Eijkenboom WM, et al. Single-dose brachytherapy versus metal stent placement for the palliation of dysphagia from esophageal cancer: Multicentre randomised trial. Lancet. 2004;364(9444):1497-1504.

10. Bergquist $\mathrm{H}$, Johnsson $\mathrm{E}, \mathrm{Nyman} \mathrm{J}$, et al. Combined stent insertion and single high-dose brachytherapy in patients with advanced esophageal cancer: Results of a prospective safety study. Dis Esophagus. 2012;25(5):410-415.

11. Zhu HD, Guo JH, Mao HW, et al. Conventional stents versus stents loaded with ${ }^{125}$ iodine seeds for treatment of unresectable esophageal cancer: A multicentre, randomized phase 3 trial. Lancet Oncol. 2014;15(6):612-619.

12. Lee $\mathrm{S}$, Osugi $H$, Tokuhara $T$, et al. Self-expandable metallic stent for unresectable malignant strictures in the esophagus and cardia. Jpn J Thorac Cardiovasc Surg. 2005;53(9):470-476.

13. Hindy P, Hong J, Lam-Tsai Y, Gress F. A comprehensive review of esophageal stents. Gastroenterol Hepatol (NY). 2012;8(8):526-532. 